\title{
Management of epilepsy
}

\section{T Deonna}

\section{Can quality of care be improved?}

n the past 15 years, 16 reviews on new discoveries in epilepsy and on various aspects of its diagnosis and management, and 273 articles in which the keyword "epilepsy" appears, have been published in Archives of Disease in Childhood. So why another review article on management-are things moving so fast?

One of these articles ${ }^{1}$ mentioned four areas of advances in epilepsy: (1) diagnostic precision; (2) drug therapy; ${ }^{2}$ (3) neuroimaging; and (4) "greater awareness of the central importance of patient and family perceptions of the condition with efforts to provide a "model of care"',

This last aspect is the most difficult to evaluate and translate into practice, and has received much less attention than discoveries in genetics, ${ }^{3}$ brain imaging, epilepsy surgery, and electrophysiology, but it can make a large difference in the impact of the disease on the child and his or her family. It is probably the most important aspect of management for the majority of children with epilepsy, who have no other handicap than occasional seizures, but whose family life, psychological wellbeing, and school progress can suffer greatly from an otherwise often benign condition with good prognosis. This review will show how this new knowledge can change the perception of the disease and its overall burden if they are integrated at all levels of care (box 1).

The following discussion focuses mainly on the $80 \%$ of epileptic children in the population who have "epilepsy only". The $20 \%$ of children with severe intractable epilepsies such as "epileptic encephalopathies" (Lennox-Gastaut syndrome, severe polymorphic epilepsy of infancy, some cases of myoclonic-astatic epilepsy) or other refractory partial epilepsies give a biased view of epilepsy to the general public, but also to young doctors who see these on an emergency basis in the hospital in status epilepticus. These children occupy the greatest part of the specialised paediatrician's or neurologist's time and efforts. These severe epilepsies are a regular topic for congresses and specialised journals, and the affected children are most often cared for in major centres. ${ }^{17}$ Do the more common and less severe epilepsies deserve less attention, are they easier to handle, and is the burden of the disease negligible?

Somewhat paradoxically, these apparently simple epilepsies deserve the same attention, because precise diagnosis and management can make an enormous difference in the quality of life and wellbeing of the child. Even though one knows that these children will recover, the impact of the disease during a significant part of their childhood is far from negligible. Furthermore, the dichotomy between benign and severe epilepsies depends on the criteria chosen and on the moment in the evolution of the disease where one happens to be. A stormy onset, or periods with very frequent seizures which are hard to control, can occur despite a subsequent easy course and definitive remission.

By definition, epileptic manifestations in a developing brain change with age

\section{Box 1: Summary of new data relevant for clinical practice}

\section{Progress in genetics of epilepsy}

- Several focal epilepsies, besides the classical rolandic epilepsies, can be hereditary, such as nocturnal frontal epilepsy ${ }^{4}$ or familial temporal epilepsy. ${ }^{5}$ They usually have a good prognosis or are easily treatable ${ }^{6}$

- Children with febrile convulsions may also have afebrile seizures or belong to a family in which other members have epilepsy, usually benign. ${ }^{7}$ The old dichotomy between simple febrile seizures and epilepsy triggered by fever no longer holds true

Brain imaging

Availability of magnetic resonance imaging allows more frequent aetiological diagnosis, thus decreasing the number of "idiopathic" cases. Surgically treatable lesions are occasionally found

\section{Epilepsy surgery}

Temporal lobe epilepsies, most often due to mesial temporal sclerosis and which are often refractory to medical therapy, can be treated surgically with excellent prognosis. An increasing number of intractable focal epilepsies can now be treated surgically 10

\section{Antiepileptic drugs}

New drugs have been found to be effective in specific indications: vigabatrin for treatment of infantile spasms, ${ }^{11}$ topiramate for partial lesional epilepsies, ${ }^{12}$ and sulthiame for idiopathic partial epilepsies. ${ }^{13} 14$

More efficient use of known drugs (doses, slow release preparations), side effects of drugs, ${ }^{15}$ and new therapeutic options (treatment of acute seizures with rectal diazepam; and more recently, nasal or buccal midazolam by parents at home, or in schools) can make a big difference. ${ }^{16}$ 
Table 1 Childhood epileptic syndromes with generally good prognosis

\begin{tabular}{|c|c|}
\hline Syndrome & Comment \\
\hline Benign neonatal familial convulsions & $\begin{array}{l}\text { Dominant, may be severe and resistant during a few days. Febrile or afebrile seizures (benign) may occur } \\
\text { later in a minority }\end{array}$ \\
\hline $\begin{array}{l}\text { Infantile familial convulsions } \\
\text { Febrile convulsions }\end{array}$ & $\begin{array}{l}\text { Dominant, seizures often in clusters (overlap with benign partial complex epilepsy of infancy) }{ }^{25} \\
\text { In some families, febrile and afebrile convulsions occur in different members, the so-called GEFS }+ \\
\text { (generalised epilepsy with febrile seizures }+ \text { ); the old dichotomy between febrile convulsions or epilepsy } \\
\text { does not always hold }\end{array}$ \\
\hline Benign myoclonic epilepsy of infancy ${ }^{26}$ & Often seizures during sleep, one rare variety with reflex myoclonic seizures (touch, noise) \\
\hline Partial idiopathic epilepsy with rolandic & The most frequent; see box 2 \\
\hline Idiopathic occipital partial epilepsy & $\begin{array}{l}\text { Early childhood form with seizures during sleep and ictal vomiting, may present as status epilepticus. }{ }^{25} 27-29 \\
\text { Later forms with migrainous symptoms; not always benign }{ }^{30}\end{array}$ \\
\hline Petit mal absence epilepsy & $\begin{array}{l}\text { Cases with absences only, some have generalised seizures. } 60-80 \% \text { full remission; in most cases, } \\
\text { absences disappear on therapy but there are resistant cases (unpredictable) }\end{array}$ \\
\hline Juvenile myoclonic epilepsy & $\begin{array}{l}\text { Adolescence onset, with early morning myoclonic seizures and generalised seizures during sleep; often } \\
\text { history of absences in childhood }\end{array}$ \\
\hline
\end{tabular}

be only confirmatory of a previously made clinical opinion. ${ }^{20}$

One should be aware of this pitfall and not be pushed into making the diagnosis in an uncertain situation. A period of waiting is never a real health risk for the child, and the issue may often be clarified in a short period of time. If there are no recurrences, either the event was not epileptic in nature or was a very benign form with rare seizures. This begs the apparent simple question of the definition of epilepsy: classically this is defined as the occurrence of recurrent unprovoked seizures. In this sense one seizure is not epilepsy, but what about one seizure occurring every six months or once a year? The term unprovoked is also a problem. Epileptic seizures in a predisposed individual occur because the balance between excitation and inhibition is temporarily upset by some external or internal factor: lack of sleep, infection, fever, stress, sensory precipitants, etc. Families often recognise them and mistake these as the primary cause. In some children, it is only when these factors accumulate or are very marked that seizures do occur. Also, seizures can change with age and brain maturation, and follow up may clarify the diagnostic issue.

For all these reasons, a firm diagnosis of epilepsy may take some time. Although diagnosis as well as the decision to give antiepileptic therapy is often perceived as an urgent matter, there will be no harm to the child if the decision is not made straight away. Such a situation is difficult to understand for the families, and is rather unusual in modern medicine, where one believes that a laboratory test will prove or disprove the diagnosis right away. This may contribute to a lack of confidence on the part of the parents or to the feeling that little is known about the condition. It must be discussed openly, insisting that no time is being lost.

\section{AETIOLOGICAL DIAGNOSIS AND DIAGNOSIS OF EPILEPTIC SYNDROMES}

There are several epileptic syndromes whose diagnosis can be made at the first seizure or early in the course by combining seizure and EEG characteristics, circumstances of occurrence, family history, etc. ${ }^{21} 22$ Table 1 lists those epileptic syndromes in normal children without brain lesion and which have a good prognosis. Rolandic epilepsy with centrotemporal spikes is the most frequent (box 2). It is crucial to have all possible information in order to make a definite diagnosis, or at least to suspect it if all necessary characteristics are not available or when there are some unusual features. When this diagnosis or another clear-cut epilepsy syndrome diagnosis can be made (epilepsy with petit mal absences, myoclonic epilepsy of infancy, juvenile myoclonic epilepsy) there is no need for further diagnostic work-up. This will allow one to decide which therapy, if any, is needed and to predict a possible very good prognosis. ${ }^{23}{ }^{24}$ Magnetic resonance imaging (MRI) of the brain is necessary only for those cases in which no clear-cut diagnosis of an idiopathic partial epilepsy or primarily generalised epilepsy

\section{Box 2: Benign partial epilepsy with rolandic spikes}

- Partial seizures ("sylvian" seizures: face, pharynx, respiratory noises) may appear generalised (seconday generalisation)

- Seizures mostly in relation to sleep ( falling asleep, early morning, change in sleep habits)

- EEG: typical "focal sharp waves" (FSW) in centrotemporal region, but location may vary; multiple independent foci; sometimes only present in sleep record EEG, usually more alarming than clinical state (normal!)

- Most cases rare seizures, $100 \%$ good prognosis, treatment often not necessary

- Occasionally long and frequent seizures and atypical forms (other seizures)

- Temporary behaviour-cognitive problems in active phase of disease possible

- Genetically determined epilepsy ${ }^{32}$ 
on allopathic medical therapy in general. These factors are so different from one epilepsy type to the other and from one family to another family that valid guidelines are difficult to establish. If one accepts that not all epilepsies need prophylactic medical therapy and that no risk usually occurs from a waiting period in doubtful situations, this leaves time for thinking. An abrupt severe onset of epilepsy (that is, status) or a bout of several seizures in a short period justify immediate therapy, whose prolonged subsequent need can be subsequently reconsidered. The introduction of treatment without a previous discussion and the family's clear comprehension of its implications may be a bad start, especially if the therapy is ill tolerated, and may preclude confidence and good compliance later on. The physician often finds himself uncertain of the necessity of therapy when the family expects it, and on the other hand considers it is an obvious decision to be made which needs no further discussion with unconvinced parents.

The question of the duration of therapy is always in the parent's mind from the onset of treatment. It is often not directly asked because parents understand that the doctor does not know and that it depends on many unknown factors. They feel caught in a long term decision with little hope of an end. Knowing that withdrawal is frequently a possibility without compromising the final remission can be very reassuring. The trend is now for shorter duration of therapy, even in cases with lesional but not very active epilepsies. There must be a discussion of the statistical and personal elements available to the physician when making the decision to propose withdrawal after a given period of time in the particular epilepsy being treated. It may be difficult for the parents to accept that there are no simple laboratory test which can show, as in many diseases, when the cure has been achieved, and that several different factors enter into the decision.

Statistical risk of recurrence is one thing; the fear of recurrences and the perception and philosophy of risk in general in the child and his parents is another very different one. ${ }^{33-35}$ It can certainly influence the doctor's judgement in favour of or against withdrawal, but the doctor should make the final decision. Sometimes, strong encouragement to attempt withdrawal is necessary, this is rarely regretted. There are two extreme situations which make the difficult decision of withdrawal easier. The first is when compliance is uncertain, the drug (or any drug) is poorly tolerated, and when the desire to stop treatment is clearly expressed or strongly felt by the physician or patient. At the other extreme, a marked fear of recurrence of seizures, a good drug tolerance and acceptance, a stabilised life situation, and no desire or reluctance to attempt withdrawal would favour continuation. When the epilepsy itself manifested with behavioural and cognitive problems which resolved on therapy, this may be another argument to continue therapy. Discussion about all these issues can prepare the ground for a decision at a later date, but not too far away. Also, the main goal of antiepileptic therapy is sometimes not to prevent the recurrence of seizures (which may be rare and harmless) but to treat what are sometime direct cognitive consequences of epileptic discharges in brain areas important for cognitive functions (see next section).

The treatment of acute seizures at home by parents with rectal diazepam or buccal midazolam has been a major progress and a relief for families, especially in the child who has chronic epilepsy and prolonged seizures or clusters of seizures (brief seizures do not need treatment and in some cases there is an unnecessary overuse of benzodiazepines). It has also made possible the intermittent drug management of some epilepsies with very rare but prolonged and severe seizures, or seizures arising only in special circumstances.

\section{COGNITIVE-BEHAVIOURAL MANIFESTATIONS OF EPILEPSY (BOX 3)}

Recurrent seizures are sometime only the most visible manifestation of a neurophysiological disorder which can have insidious, chronic, and subtle effects in the cognitive-behavioural domain. Only recently has this dimension of childhood epilepsy really emerged..$^{36}$ Its recognition and differentiation from all other factors (underlying brain pathology, psychological factors, drug side effects) require an approach which is totally different from classical seizure management and represents an important change of view on epilepsy. It is usually included in the literature under the broad category of psychosocial factors, but it is not the same issue. One is dealing here with direct manifestations of epilepsy in neuronal circuits and systems devoted to cognitive functions and emotions, rather than to simple motor, sensory, or vegetative functions.

These cognitive and behavioural disturbances can be mistaken for a psychological problem and are not necessarily related to the severity or number of seizures; they can occur in otherwise "benign" epilepsies. The approach to these problems requires cooperation with several professionals and contact by the clinician with school staff. The evaluation of therapy in such situations is very different from that of seizure counts and IQ tests, and is a new challenge in childhood epilepsy and a field of active research. Box 3 shows the various epilepsy situations or syndromes in which this dimension of epilepsy has become revealed and can be particularly studied.

Prolonged cognitive and behavioural symptoms can be the only or main symptom in some epilepsy syndromes such as acquired epileptic aphasia (Landau-Kleffner syndrome) and partial epilepsy with continuous spike-waves during sleep. One has to rely exclusively on EEG findings showing frequent paroxysmal focal (the so-called focal sharp waves) and generalised epileptic activity. Many of the clinical and EEG features of the Landau-Kleffner syndrome are seen in benign partial epilepsy with rolandic spikes and it probably represents the extreme severe end of the spectrum of this syndrome. ${ }^{43}$ In fact, mild cognitive and behavioural symptoms do occur more often than previously realised in the active epilepsy phase of rolandic epilepsy. ${ }^{44}$

Another very important source of information on the possible behavioural manifestations of epilepsy in children comes from studies of newly diagnosed epilepsies. A much higher incidence of behavioural problems has been found in these children than in controls in the months preceding the first recognised seizures. It strongly suggests the possibility of a direct behavioural effect of epilepsy because they can not be attributed to the psychological consequences of the diagnosis of epilepsy or to side effects of antiepileptic drugs. When the child's behaviour improves rapidly and markedly with antiepileptic therapy, this constitutes a further confirmation. In practice, these situations are only seen occasionally, and parents who have had this experience realise that epilepsy sometimes involves more than the visible seizures. Systematic study of these situations with precise documentation of cognitive and behavioural symptoms would be most interesting, but has not been done to our knowledge.

\section{PERCEPTION OF THE DISEASE AND SECONDARY PREVENTION}

Children with epilepsy often suffer as much or even more from the psychological consequences of the diagnosis than from the seizures themselves. ${ }^{45-48}$ Most children have symptoms only for a few minutes or hours of their life, and they only occur every few weeks or months. Children with frequent 
Box 3: Cognitive and behavioural manifestations of epilepsy. Epilepsy situations or syndromes in which their importance has been recognised and their study undertaken

- Prolonged ictal/postictal cognitive deficits in partial epilepsies. These may last for days or weeks

- Transient cognitive impairment (TCI) during EEG discharges but without recognisable clinical seizures or measurable deficit without special tests ${ }^{38}$

- Epileptic syndromes with cognitive/behavioural manifestation as the main or only symptom: acquired epileptic aphasia (Landau-Kleffner syndrome and partial epilepsy with continuous spike-waves during sleep $)^{39}$

- Newly diagnosed epilepsies with behavioural symptoms before the first seizures have been recognised ${ }^{40-42}$

- Surgically treated epilepsies when rapid cognitive-behavioural improvement can be directly attributed to seizure remission

migraine headaches are sometimes much more handicapped. Families' and doctor's perceptions of the disease are different. The term "to control" seizures betrays the fear that lack of control or loss of control (meaning that seizures occur despite antiepileptic drugs) represents a failure, a danger, or an ominous sign that some permanent damage will ensue. This is not true for the majority of epilepsies. Epilepsies follow their own natural course and final remission does not depend on successful prophylactic therapy. The risk of accidents due to a seizure is barely or not at all more frequent than in non-epileptic children. ${ }^{49}$ This is probably because seizures mainly occur during states of decreased vigilance (somnolence, sleep, arousal, meals) and much less during intense physical or mental activity. Despite this knowledge, the natural tendency of parents to overprotect the child, an attitude which is sometime encouraged by physicians, can be psychologically devastating. ${ }^{49-52}$

As in most diseases, but probably more so with epilepsy, the parent's perceptions of the disorder will be influenced by their prejudices and personal acquaintance with it. ${ }^{53}$ Families with other affected members (siblings, parents) react very differently from those who discover epilepsy when their child has his or her first seizure. The severity and potential frightening experience of the first encounter with epilepsy in their child (screaming, cyanosis, incontinence) and the circumstances of the occurrence (unpleasant or potentially dangerous situation) may leave a mark or signature which will determine their future vision of epilepsy, even though it may never repeat itself in the same way. In some cases, the change in behaviour during the post-ictal state (confusion, fatigue, slow thinking) may engender the fear that epilepsy will in the future alter brain function and intelligence in a permanent fashion.

Discussion of all these often unspoken fears with the physician, and explaining to the child his problem and encouraging his questions openly is an important, if not the most important, part of epilepsy management. It is easier said than done. After having discussed seizure history, drug treatment, general health, development, behaviour, and school problems, little time is usually left for further discussion, particularly when parents are uncertain that their fears will be listened to, but sometime also because they have not even formulated them to themselves. The physician may also think that good or total seizure control is enough to dispel most worries and stops there, but this is often not the case. To understand that, it is enough to remember the perfectly normal child with a very benign epilepsy whose family life and the family's vision of their child have been seriously affected.

Information on epilepsy from parents' associations, television programmes, personal testimonies of affected persons in books or magazines, use of the internet, and the recording of seizures with videos at home by parents have certainly improved public awareness of the problem. We have reviewed 19 documents published by epilepsy associations of various countries, looking in particular at whether the perception of the disease and the fears alluded to above were actually addressed. Most had a considerable amount of useful factual information on epilepsy itself, but often limited attempts to imagine families' and children's beliefs and often unspoken concerns about the disease. These are, for instance, the fear of death due to seizures, ${ }^{54}$ risks of accidents due to a seizure, ${ }^{49}$ the numerous deleterious myths about epilepsy (epileptic personality, confusion with mental disorders, the fear that intense physical or mental activity can provoke seizures). Some leaflets have unjustifiably anxiety raising or counter-productive messages, such as "each seizure paves the way for the next".

Families will greatly differ in the type of worries they have and in their ability to express them. Experience shows that they should be encouraged to do so. There are many unanswered or initially unimagined concerns which come out during clinical controls. The discussion of potential worries in anticipation by the physician can also be very useful. Asking parents to write down their questions, even in a blank sheet in the waiting room, can lead to surprises and can open the communication. This aspect cannot be replaced by information leaflets, even though these can be very useful and help to open a dialogue.

\section{MANAGEMENT OF CRISIS SITUATIONS}

The first seizure seen by the parents and the moment when the diagnosis of epilepsy is made are the major initial crises in the experience of the disease. When seizures are fully controlled, but also when they recur without visible harm to the child, a somewhat surprising calm and adequate reaction can be seen in the parents, which one would not have imagined after the first event. This crisis may last for a short period, but may also spread over several months of anxiety or disbelief. It is rare that the implications of the disease and the parents' questions have been discussed at this time, although there may be no better time for different practical reasons.

Another crisis is when a change in the type of seizures occurs ("he never had one like this"). Sometimes a sudden flurry of seizures, or an unexpectedly long or severe seizure (status epilepticus) occurs after a prolonged seizurefree period. This may lead to a new crisis in which all hope seems lost and confidence into the physician is put into question. This also occurs when a new drug is not only ineffective but increases seizures and produces marked side effects. In these situations, the parents may feel that the physician is not only unhelpful, but is actually harming their child. One should be prepared for this and be supportive and acknowledge the parents' and child's momentary despair and one's own feeling of helplessness.

Another crisis is when withdrawal is attempted and seizures recur. This is a huge disappointment and conveys a feeling that everything is lost. One should prepare the family that this can happen. One seizure during withdrawal does not necessarily mean restarting 
long term therapy, because isolated seizures can occur during this period.

\section{CHANGING ONE'S ATTITUDE TOWARDS EPILEPSY}

If one should not underestimate the social and other burdens of having epileptic seizures, and the change in some children's lives when these are suppressed effectively, the obsession to control seizures and the view that each seizure is a failure of management or an ominous sign for the future should be put into question. This is difficult for some physicians raised in the old and unjustified myth that "seizures begets seizures" and that brain damage may result from seizures. This does not happen in the great majority of epilepsies. When it occurs, one is usually dealing with unpreventable and very special situations.

An epileptic seizure is one of many kinds of transient cerebral dysfunction. However, it is not accepted, as are, for instance, sometimes more handicapping severe migraine headaches or frequent syncopes. The behaviour of a child during a seizure can indeed be a more frightening experience, but its impact also results from the stigma attached to the manifestation. The attitude of physicians and other professionals, especially schoolteachers, plays an important role.

Being old enough to have witnessed children with benign febrile convulsions on chronic phenobarbitone, normal children with partial "idiopathic" epilepsies subjected to angiography, or epileptic children prevented from sports or other activities from fear of accidents, this author cannot avoid thinking that some progress has been made, but also worries what our successors will think of our present shortcomings and dogmas.

Arch Dis Child 2005;90:5-9.

doi: 10.1136/adc.2003.032656

Correspondence to: $\operatorname{Dr} T$ Deonna Neuropaediatric Unit, Univ. Children's Hospital, CHUV, CH-1011 Lausanne, Switzerland; tdeonna@hotmail.com

Accepted 29 May 2004

\section{REFERENCES}

1 Kennedy CR. Advances in neurology. Arch Dis Child 1996:75:251-5.

2 Appleton RE. The new antiepileptic drugs. Arch Dis Child 1996;75:256-62.

3 Robinson R, Gardiner M. Genetics of childhood epilepsy. Arch Dis Child 2000;82:121-5.

4 Provini F, Plazzi G, Tinuper P, et al. Nocturnal frontal lobe epilepsy. A clinical and polygraphic overview of 100 consecutive cases. Brain 1999; 122:1017-31.
5 Santos NF, Sousa SC, Kobayashi E, et al. Clinical and genetic heterogeneity in familial temporal lobe epilepsy. Epilepsia 2002;43(suppl 5):136.

6 Picard F, Baulac S, Kahane P, et al. Dominant partial epilepsies. A clinical, electrophysiological and genetic study of 19 European families. Brain 2000; 123(pt 6):1247-62

7 Scheffer IE, Berkovic SF. Generalized epilepsy with febrile seizures plus. A genetic disorder with heterogeneous clinical phenotypes. Brain 1990;31(suppl 3):S19-29.

8 Singh R, Scheffer IE, Crossland K, et al. Generalized epilepsy with febrile seizure plus (GEFS): a common childhood onset, genetic epileptic syndrome. Ann Neurol 1999;45:75-81.

9 Cross JH. Update on surgery for epilepsy. Arch Dis Child 1999;81:356-9.

10 Polkey CE. Alternative surgical procedures to help drug-resistant epilepsy-a review. Epileptic Disord 2003;5:93-100.

11 Riikonen R. Steroids or vigabatrin in the treatment of infantile spasms? Pediatr Neurol 2000;23:403-8

12 Mikaeloff Y, de Saint-mMartin A, Mancini J, et al. Topiramate: efficacy and tolerability in children according to epilepsy syndromes. Epilepsy Res 2003:53:225-32.

13 Rating D, Wolf C, Bast T. Sulthiame as monotherapy in children with benign childhood epilepsy with centrotemporal spikes; a 6-month randomized, double-blind, placebo-controlled study. Sulthiame Study Group. Epilepsia 2000;41:1284-8

14 Engler F, Maeder-Ingvar M, Roulet E, et al. Treatment with sulthiame (Ospolot) in benign partial epilepsy of childhood and related syndromes: an open clinical and EEG study. Neuropediatrics 2003;34:105-9.

15 Perucca E, Gram L, Avanzini G, et al Antiepileptic drugs as a cause of worsening of seizures. Epilepsia 1998:39:5-17.

16 Jeannet PY, Roulet E, Maeder-Ingvar M, et al. Home and hospital treatment of acute seizures in children with nasal midazolam. Eur J Pediatr Neurol 1999:3:73-7.

17 Livingston JH. Management of intractable epilepsy. Arch Dis Child 1991;66:1454-6.

18 Stephenson JBP. Fits and faints. Clinics in developmental medicine. No. 109. Oxford: MacKeith Press, 1990

19 Kotagal P, Costa M, Wyllie E, et al. Paroxysmal nonepileptic events in children and adolescents. Pediatrics 2002; 1 10:E4-6

20 Verity CM. The place of the EEG and imaging in the management of seizures. Arch Dis Child 1995;73:557-62

21 Aicardi J. Epileptic syndromes in childhood Epilepsia 1988;29(suppl 3):S1-5.

22 Deonna T, Ziegler AL. Epilepsies dites "bénignes" de l'enfant. Revue Médicale de la Suisse Romande 1994;114:861-7.

23 Loiseau P, Duché B, Cordova S, et al. Prognosis of benign childhood epilepsy with centrotemporal spikes: a follow-up study of 168 patients. Epilepsia 1988;29:229-35.

24 Peters JM, Camfield PR. Population study of benign rolandic epilepsy: is treatment needed? Neurology 2001;57:537-9.

25 Vigevano F, Cusmai R, Ricci S, et al. Benign epilepsy of infancy. In: Engel J, Pedley TA, eds. Epilepsy: a comprehensive textbook. Philadelphia Lippincott-Raven, 1997:1126-76.

26 Lin $\mathrm{Y}$, Itomi K, Takada H, et al. Benign myoclonic epilepsy in infants: video-EEG features and longterm follow-up. Neuropediatrics 1998;29:268-71

27 Panayotopoulos CP. Early-onset benign childhood occipital seizure susceptibility syndrome: a syndrome to recognize. Epilepsia 1999;40:621-30

28 Panayiotopoulos CP. Benign childhood partial epilepsies: benign childhood seizure susceptibility syndrome. J Neurol Neurosurg Psychiatry 1993:56:2-5

29 Kivity S, Lerman P. Stormy onset with prolonged loss of consciousness in benign childhood epilepsy with occipital paroxysms. J Neurol Neurosurg Psychiatry 1992;55:45-8.
30 Andermann F, Zifkin B. The benign occipital epilepsies of childhood: an overview of the idiopathic syndromes and of the relationship to migraine. Epilepsia 1998;39:S9-23.

31 Panayiotopoulos CP. Typical absence seizures and their treatment. Arch Dis Child 1999;81:351-5.

32 Neubaver BA, Fiedler B, Himmelein B, et al. Centrotemporal spikes in families with rolandic epilepsy: linkage to chromosome 15q14. Neurology 1998;51:1608-12

33 Shinnar S, Berg AT, Moshé SL, et al. Discontinuing antiepileptic drugs in children with epilepsy: a prospective study. Ann Neurol 1994;35:534-45.

34 Braathen G, Anderson T, Gylie H, et al. Comparison between one and three years of treatment in uncomplicated childhood epilepsy: a prospective study. I. Outcome in different seizure types. Epilepsia 1996;37:822-32.

35 Maytal J, Shinnar S, Moshé SL, et al. Low morbidity and mortality of status epilepticus in children. Pediatrics 1989:83:323-31.

36 Deonna T. Cognitive and behavioural correlates of epileptic activity in children. J Child Psychol Psychiatry 1993;34:611-20.

37 Deonna T. Cognitive and behavioral manifestations of epilepsies in children. Cognitive epilepsies. In: Wallace S, Farrel K, eds. Epilepsy in children, 2nd edn. London: Arnold, 2002.

38 Kasteleijn-Nolst-Trenite DG. Transient cognitive impairment during subclinical epileptiform EEG discharges. Semin Pediatr Neurol 1995;2:246-53

39 Appleton RE. The Landau Kleffner syndrome. Arch Dis Child 1995;13:1243-4.

40 Austin JK, Harezlak J, Dunn DW, et al. Behavior problems in children before first recognized seizure. Pediatrics 2001;107:115-22.

41 Austin JK, Dunn DW, Caffrey HM, et al. Recurrent seizures and behavior problems in children with first recognized seizures: prospective study. Epilepsia 2002;43:1564-73.

42 Austin JK, Dunn DW. Progressive behavioral changes in children with epilepsy. In: Sutula T, Pitkainen A, eds. Progress in brain research. Elsevier BV, 2002:135:419-27.

43 Fejerman N, Caraballo R, Tenembaum SN. Atypical evolutions of benign localization-related epilepsies in children: are they predictable? Epilepsia 2000;41:380-90.

44 Deonna T. Rolandic epilepsy: neuropsychology of the active epilepsy phase. Epileptic Disorders 2000;2:559-61.

45 Voeller KKS, Rothenberg MB. Psychosocia aspects of the management of seizures in children. Pediatrics 1973;51:1072-82.

46 Ronen GM, Rosenbaum P, Law M, et al. Healthrelated quality of life in childhood epilepsy: the results of children's participation in identifying the components. Dev Med Child Neurol 1999:41:554-9

47 Mitchell WG. Social outcome of childhood epilepsy: associations and mechanisms. Semin Pediatr Neurol 1994:1:136-43.

48 Deonna T. Childhood epilepsy: secondary prevention is crucial. Dev Med Child Neurol 2003; (suppl):38-41.

49 Ziegler AL, Reinberg O, Deonna T. Epilepsie et acccidents. Quel risque chez l'enfant? Archives Françaises de Pédiatrie 1994;1:801-5.

50 Lerman $\mathbf{P}$. The concept of preventive rehabilitation in childhood epilepsy: a plea against overprotection and overindulgence. In: Penry JK, ed. Epilepsy, the eighth international symposium. New York: Raven Press, 1977:265-8.

51 Carpay HA, Vermeulen J, Stroink H, et al. Disability due to restrictions in childhood epilepsy. Dev Med Child Neurol 1997;39:521-6.

52 International League Against Epilepsy Commission Report. Restrictions for children with epilepsy. Epilepsia 1997;38:1054-6.

53 Ellis N, Upton D, Thompson P. Epilepsy and the family: a review of current literature. Seizure 2000;9:22-30.

54 Appleton RE. Mortality in pediatric epilepsy. Arch Dis Child 2003;88:1091-4. 